\title{
Applying simple water-energy balance frameworks to predict the climate sensitivity of streamflow over the continental United States
}

\author{
M. Renner and C. Bernhofer \\ Technische Universität Dresden, Faculty of Forest-, Geo- and Hydro Sciences - Institute of Hydrology and Meteorology - \\ Chair of Meteorology, Pienner Str. 23, 01737 Tharandt, Germany
}

Correspondence to: M. Renner (maik.renner@mailbox.tu-dresden.de)

Received: 23 November 2011 - Published in Hydrol. Earth Syst. Sci. Discuss.: 9 December 2011

Revised: 26 June 2012 - Accepted: 2 July 2012 - Published: 7 August 2012

\begin{abstract}
The prediction of climate effects on terrestrial ecosystems and water resources is one of the major research questions in hydrology. Conceptual water-energy balance models can be used to gain a first order estimate of how long-term average streamflow is changing with a change in water and energy supply. A common framework for investigation of this question is based on the Budyko hypothesis, which links hydrological response to aridity. Recently, Renner et al. (2012) introduced the climate change impact hypothesis (CCUW), which is based on the assumption that the total efficiency of the catchment ecosystem to use the available water and energy for actual evapotranspiration remains constant even under climate changes.

Here, we confront the climate sensitivity approaches (the Budyko approach of Roderick and Farquhar, 2011, and the CCUW) with data of more than 400 basins distributed over the continental United States. We first estimate the sensitivity of streamflow to changes in precipitation using long-term average data of the period 1949 to 2003. This provides a hydro-climatic status of the respective basins as well as their expected proportional effect to changes in climate. Next, we test the ability of both approaches to predict climate impacts on streamflow by splitting the data into two periods. We (i) analyse the long-term average changes in hydro-climatology and (ii) derive a statistical classification of potential climate and basin change impacts based on the significance of observed changes in runoff, precipitation and potential evapotranspiration. Then we (iii) use the different climate sensitivity methods to predict the change in streamflow given the observed changes in water and energy supply and (iv) evaluate the predictions by (v) using the statistical classification scheme and (vi) a conceptual approach to separate
\end{abstract}

the impacts of changes in climate from basin characteristics change on streamflow. This allows us to evaluate the observed changes in streamflow as well as to assess the impact of basin changes on the validity of climate sensitivity approaches.

The apparent increase of streamflow of the majority of basins in the US is dominated by an increase in precipitation. It is further evident that impacts of changes in basin characteristics appear simultaneously with climate changes. There are coherent spatial patterns with catchments where basin changes compensate for climatic changes being dominant in the western and central parts of the US. A hot spot of basin changes leading to excessive runoff is found within the US Midwest. The impact of basin changes on the prediction is large and can be twice as much as the observed change signal. Although the CCUW and the Budyko approach yield similar predictions for most basins, the data of water-limited basins support the Budyko framework rather than the CCUW approach, which is known to be invalid under limiting climatic conditions.

\section{Introduction}

\subsection{Motivation}

The ongoing debate of environmental change has stimulated many research activities, with the central questions of how hydrological response may change under (i) climate change and (ii) under changes of the land surface. These questions are also practically of high concern, because present management plans are needed to cope with the anticipated changes 
in the future. Therefore, robust and reliable estimates of how water supplies are changing under a given future scenario are needed.

The link between climate change and hydrological response, which we will refer to as climatic sensitivity, is one of the central research questions in past and present hydrology. There are different directions to settle this problem. One direction of research tries to model all known processes operating at various temporal and spatial scales in complex Earthclimate simulation models, hoping to represent all processes with the correct physical description, initial conditions and parameters. These exercises are compelling; however, it is hard to quantify all uncertainties of such complex systems (Blöschl and Montanari, 2010).

Another direction is to deduce a conceptual description valid for the scale of the relevant processes of interest (Klemes, 1983). For example, the Budyko hypothesis has successfully been used as a conceptual model to derive analytical solutions to estimate climate sensitivity of streamflow and evapotranspiration (Dooge, 1992; Arora, 2002; Roderick and Farquhar, 2011; Yang and Yang, 2011). A different conceptual approach has been taken by Renner et al. (2012), who use the concept of coupled long-term water and energy balances to derive analytic solutions for climate sensitivity. This concept is a theoretical extension of the ecohydrological framework of Tomer and Schilling (2009), who provide a simple framework to separate climatic impacts on the hydrological response from other impacts such as land cover change.

Before applying any method for the unknown future, it needs to be evaluated by using historical data. Preferably for the case of streamflow sensitivity, the data are at the spatial scale of water resources management operations; the data should be homogeneous, consistent, and cover a variety of climatic and hydrographic conditions.

\subsection{Hydro-climate of the continental US}

We found that the situation in the continental US fulfils many of these points, and the agenda to publish data with free and open access clearly supported our research. Here, we employ data of the Model Parameter Estimation Experiment (MOPEX) of the US (Schaake et al., 2006), covering the second part of the 20th century in the US.

This period is particularly interesting, because significant hydro-climatic changes have been reported (Lettenmaier et al., 1994; Groisman et al., 2004; Walter et al., 2004). Most prominent is the increase of precipitation for a large part of the US in the 1970s (Groisman et al., 2004). Also streamflow records show predominantly positive trends (Lins and Slack, 1999); however, there are still open research questions regarding the resulting magnitudes and the causes of different responses to the increase in precipitation (Small et al., 2006).

Specifically, there is the need to quantify climatic impacts such as changes in precipitation or evaporative demand on streamflow. As Sankarasubramanian et al. (2001) note, there are large discrepancies in climatic sensitivity estimates, not only due to the model used, but also its parametrisation can obscure estimated links between climate and hydrology.

Furthermore, there is evidence of human-induced changes in the hydrographical features of many basins, especially land-use changes, dam construction and operation, and irrigation; but also changes in forest and agricultural management practices are believed to have considerable impacts on the hydrological response of river basins (Tomer and Schilling, 2009; Wang and Cai, 2010; Kochendorfer and Hubbart, 2010; Wang and Hejazi, 2011). Yet, there is the difficulty to separate effects of changes in basin characteristics and those of climate variations, which operate on different temporal scales (Arnell, 2002).

\subsection{Aims and research questions}

This paper presents an evaluation of two conceptual hypotheses, the newly developed water-energy balance framework of Renner et al. (2012) and the Budyko framework presented by Roderick and Farquhar (2011) to estimate climate sensitivity of streamflow. We evaluate both frameworks by applying them to a large dataset describing the observed hydroclimatic changes within the continental US in the second part of the 20th century. We further aim to quantify the impact of climatic changes on streamflow under the concurrence of climatic variations and changes in basin characteristics in the US.

Specifically we address the following research questions:

1. Can we predict and attribute the streamflow changes to the respective changes in precipitation and evaporative demand?

2. How strong is the effect of estimated basin characteristic changes on (i) the change in streamflow and (ii) the sensitivity methods, which only regard climatic changes?

This paper is structured as follows. We first review the ecohydrological framework aiming to separate climate from other effects on streamflow and present the methods used to predict the sensitivity of streamflow to climate. The results are discussed in light of the rich literature already existing for the hydro-climatic changes observed over the continental US.

\section{Methods}

\subsection{Ecohydrological concept to separate impacts of climate and basin changes}

The approaches considered here aim at the long-term water and energy balance equations at the catchment scale. Thus, we assume that interannual storage changes can be neglected. 
The framework established by Tomer and Schilling (2009) represents the hydro-climatic state space of a given watershed by using two non-dimensional variables, relative excess water $W$ and relative excess energy $U$. Both variables can be derived by normalising the water balance equation with precipitation $(P)$ and the energy balance equation with the water equivalent of net radiation $\left(R_{\mathrm{n}} / L\right)$ (Renner et al., 2012):

$$
W=1-\frac{E_{\mathrm{T}}}{P}=\frac{Q}{P}, U=1-\frac{E_{T}}{R_{\mathrm{n}} / L}=1-\frac{E_{\mathrm{T}}}{E_{\mathrm{p}}} .
$$

Relative excess water $W$ considers the amount of water that is not used by actual evapotranspiration $E_{\mathrm{T}}$ and thus equals the runoff ratio (areal streamflow $Q$ over $P$ of a river catchment). Relative excess energy $U$ describes the relative amount of energy not used by $E_{\mathrm{T}}$. Note that we use potential evapotranspiration $E_{\mathrm{p}}$ instead of $R_{\mathrm{n}} / L$ to describe the energy supply term. This has practical relevance, because $E_{\mathrm{p}}$ can be estimated from widely available meteorological data.

Tomer and Schilling (2009) analysed temporal changes in $U$ and $W$ at the catchment scale. With that, they introduced a conceptual model, based on the hypothesis that the direction of a temporal change in the relationship of $U$ and $W$ can be used to distinguish effects of a change in land use or climate on the water budget in a given basin. The concept carries three interesting cases relevant for streamflow sensitivity to climate and changes in basin characteristics. First, a change in $E_{\mathrm{T}}$ without any changes in climate must evidently be caused by changes in the basin properties. Thus, both $U$ and $W$ change simultaneously. Second, a change in climate without any changes in the basin properties also leads to changes in $U$ and $W$, but in opposing directions. Taking this further we assume that

$\Delta U / \Delta W=-1$

under the presence of climate changes, which we refer to as the climate change impact hypothesis (abbreviated as CCUW). If, however, both climate and basin characteristics change, we assume that the direction of change as seen in the UW space

$\omega=\arctan \frac{\Delta U}{\Delta W}$

provides a first-order estimate on the relative importance of past climatic and basin change impacts on the hydrological response of river basins.

\subsection{Streamflow change prediction based on a coupled water-energy balance framework}

The simplicity of the climate change impact hypothesis (CCUW) allows to derive sensitivity estimates of streamflow to changes in climate. However, there are strong underlying assumptions which limit the potential use of this method (Renner et al., 2012). Ideally, the CCUW hypothesis is only valid for non-limited conditions, i.e. $P \approx E_{\mathrm{p}}$ and $E_{\mathrm{T}} / P$ sufficiently smaller than 1 . This means that, for any application, we have to assume that the CCUW is invariant to climate as well as to the hydrological response $\left(E_{\mathrm{T}}\right)$ of a certain basin. These strong assumptions can theoretically lead to conflicts with the physical laws of water and energy conservation. For example, the CCUW may predict that Budyko's water limit is crossed when the aridity index is increasing (Renner et al., 2012).

Taking these assumptions and limitations into account, the following practical relations can be deduced. First, by using the total derivative of the definitions of $W$ and $U$ in Eq. (1) and combining with the CCUW hypothesis (Eq. 2), the sensitivity coefficient of streamflow to precipitation can be derived (Renner et al., 2012):

$\varepsilon_{Q, P}=\frac{P}{Q}-\frac{(P-Q) E_{\mathrm{p}}}{Q\left(E_{\mathrm{p}}+P\right)}$.

The sensitivity coefficient $\varepsilon_{Q, P}$ describes how a proportional change in $P$ translates into a proportional change of streamflow. The sensitivity is largely dependent on the inverse of the runoff ratio and the aridity of the climate. An analogue coefficient for the sensitivity to $E_{\mathrm{p}}$ is easily derived by the connection of both coefficients: $\varepsilon_{Q, P}+\varepsilon_{Q, E_{\mathrm{p}}}=1$ (Kuhnel et al., 1991).

The CCUW hypothesis may also be used to predict absolute changes. Therefore, consider two long-term average hydro-climate state spaces $\left(\left(P_{0}, E_{\mathrm{p}, 0}, Q_{0}\right) ;\left(P_{1}, E_{\mathrm{p}, 1}, Q_{1}\right)\right)$ of a given basin. Again, by using the definitions of $W$ and $U$ and applying the CCUW hypothesis, an equation can be derived to predict the new state of streamflow $Q_{1}$ (Renner et al., 2012):

$Q_{1}=\frac{\frac{Q_{0}}{P_{0}}-\frac{P_{0}-Q_{0}}{E_{\mathrm{p}, 0}}+\frac{P_{1}}{E_{\mathrm{p}, 1}}}{\frac{1}{P_{1}}+\frac{1}{E_{\mathrm{p}, 1}}}$

Last, a direct consequence of the CCUW is that the sum of the efficiency to evaporate the available water supply $\left(E_{\mathrm{T}} / P\right)$ and the efficiency to use the available energy for evapotranspiration $\left(E_{\mathrm{T}} / E_{\mathrm{p}}\right)$ :

$C_{\mathrm{E}}=\frac{E_{\mathrm{T}}}{P}+\frac{E_{\mathrm{T}}}{E_{\mathrm{p}}}$

is constant for a given basin. Any changes in $C_{\mathrm{E}}$, which we denote as catchment efficiency, would then be assigned to a change in basin characteristics.

\subsection{Streamflow change prediction based on the Budyko hypothesis}

The Budyko hypothesis states that actual evapotranspiration is primarily determined by the ratio of energy supply $\left(E_{\mathrm{p}}\right)$ over water supply $(P)$, which we refer to as aridity in$\operatorname{dex}\left(E_{\mathrm{p}} / P\right)$. There are various functional forms which describe this relation, e.g. Schreiber (1904); Ol'Dekop (1911); 
Budyko (1948). In this paper, we use a parametric form first described by Mezentsev (1955):

$E_{\mathrm{T}}=\frac{E_{\mathrm{p}} \cdot P}{\left(P^{n}+E_{\mathrm{p}}^{n}\right)^{1 / n}} ;$

see e.g. Roderick and Farquhar (2011) for the history of this equation. The parametric form introduces a catchment parameter $(n)$, which is used to adjust for inherent catchment properties. The knowledge of the functional form $E_{\mathrm{T}}=$ $f\left(P, E_{\mathrm{p}}, n\right)$ allows to compute the sensitivity of streamflow to climatic changes $\left(P, E_{\mathrm{p}}\right)$ and to changes in the basin properties represented by $n$ (Roderick and Farquhar, 2011; Renner et al., 2012). Thereby, by applying the first total derivative of the respective Budyko function and assuming steady state conditions of the water balance with $P=E_{\mathrm{T}}+Q$, absolute changes in streamflow $(\mathrm{d} Q)$ can be predicted (Roderick and Farquhar, 2011):

$\mathrm{d} Q=\left(1-\frac{\partial E_{\mathrm{T}}}{\partial P}\right) \mathrm{d} P-\frac{\partial E_{\mathrm{T}}}{\partial E_{\mathrm{p}}} \mathrm{d} E_{\mathrm{p}}-\frac{\partial E_{\mathrm{T}}}{\partial n} \mathrm{~d} n$.

To compute the change in streamflow given some change in climate, one generally sets $\mathrm{d} n=0$. Note that using Budyko approaches for predicting the effects of a change in climate will also result in a change in $C_{\mathrm{E}}$. This change is determined by the functional form and the catchment parameter as well as the aridity index of the basin (Renner et al., 2012).

Last, by dividing by the long-term average $Q$ and term expansions, an expression can be obtained which contains the sensitivity coefficients of streamflow to $P, E_{\mathrm{p}}$ and $n$, respectively (Roderick and Farquhar, 2011):

$$
\begin{aligned}
\frac{\mathrm{d} Q}{Q} & =\left[\frac{P}{Q}\left(1-\frac{\partial E_{\mathrm{T}}}{\partial P}\right)\right] \frac{\mathrm{d} P}{P}+\left[\frac{E_{\mathrm{p}}}{Q} \frac{\partial E_{\mathrm{T}}}{\partial E_{\mathrm{p}}}\right] \frac{\mathrm{d} E_{\mathrm{p}}}{E_{\mathrm{p}}} \\
& +\left[\frac{n}{Q} \frac{\partial E_{\mathrm{T}}}{\partial n}\right] \frac{\mathrm{d} n}{n} .
\end{aligned}
$$

The sensitivity coefficients, also referred to as elasticity coefficients (Schaake and Liu, 1989), are given within the brackets. For example, a sensitivity coefficient of $\varepsilon_{Q, P}=2$ means that a relative change in precipitation of $10 \%$ amounts to a twofold change in $Q$, i.e. $20 \%$. The partial differentials for the Mezentsev function are listed in the Appendix A.

Mapping the Mezentsev function into UW space reveals that the CCUW approach can be regarded as a special case of the Budyko approach, because both are identical when $P \approx E_{\mathrm{p}}$. However, the theoretical climate change direction of the Mezentsev function $\left(\omega_{\mathrm{Mez}}\right)$ largely depends on the aridity index and on the catchment parameter $n$, whereas the CCUW assumes the climate change direction to be constant. A mathematical derivation of $\omega_{\mathrm{Mez}}$ is given in Renner et al. (2012).

\subsection{Statistical classification of potential climate and basin change impacts}

As we are aiming to test the streamflow sensitivity frameworks with historical data, we also need to take other factors of potential streamflow changes into account (Jones, 2011). Most likely are human alterations such as land-use change, change in agricultural management and other factors that influence the hydrological response of river basins. In the following, we will refer to these type of changes as basin changes.

For the retrospective analysis of past changes on river basin level, we need data of the water and energy balance components. Usually, climatic data $\left(P, E_{\mathrm{p}}\right)$ and streamflow data are available. For evaluation of potential impacts, the conceptual model of Tomer and Schilling (2009) can be used to separate climate from basin change impacts. Thereby, simultaneous changes in the water and energy balance reflected by $\Delta U$ and $\Delta W$ are investigated (Renner et al., 2012, Fig. 1).

However, it is also possible to directly investigate the changes in the hydro-climatic data by using statistical tests, e.g. testing for changes in the mean of two periods. Then, the significance results of climatic variables $\left(P, E_{\mathrm{p}}\right)$ and hydrological variables $(Q)$ can be combined to construct a data-based classification of likely impacts on streamflow change. Generally, four different hypotheses for changes in these variables can be formulated: first, the null hypothesis of "no change" in any of these variables. And three alternative hypotheses based on significant changes are possible: "climate only", "runoff only" and "climate \& runoff". So, we expect that, if climatic changes directly lead to changes in runoff, these are most likely to be found in the "climate $\&$ runoff" group. Contrarily, the other alternative hypotheses suggest that some type of basin changes occurred. Given the background signal of increased humidity, the "climate only" hypothesis suggests that there has been some compensation of climatic changes by changes in the properties of the basin. This could be vegetational responses to past disturbances such as succession, but also (natural or anthropogenic forced) adaptations of vegetation to climate changes (Jones, 2011). In contrast, the "runoff only" hypothesis suggests that factors other than the long-term average change in climate lead to changes in streamflow. A similar grouping of basins has been used by Milliman et al. (2008), who defined "normal rivers" which match with the "climate \& runoff" group, "deficit rivers" where the signal in climate is much larger than the signal in runoff, which matches with the "climate only" group. And "excess rivers" where the runoff change cannot be explained by climatic changes, which is similar to the "runoff only" hypothesis.

In this paper, we split a large dataset into two periods and test these hypotheses for each basin by evaluating the combination of two-sample t-tests results for $P, E_{\mathrm{p}}$ and $Q$. This resulted in 9 different groups, which are set as follows: if none of the three t-tests is rejected at a certain significance level $\alpha$, we define this as "no change", denoted as "-" in the figures and tables. If, for example, $P$ and $E_{\mathrm{p}}$ changed significantly, while $Q$ did not, we denote this group as " $P, E_{\mathrm{p}}$ ". 


\section{Data}

The aforementioned approaches are not very data demanding. Still longer time series of annual basin precipitation totals $\left(P\left[\mathrm{~mm} \mathrm{yr}^{-1}\right]\right)$, river discharge data converted to areal means $\left(Q\left[\mathrm{~mm} \mathrm{yr}^{-1}\right]\right)$ and potential evapotranspiration data $\left(E_{\mathrm{p}}\left[\mathrm{mm} \mathrm{yr}^{-1}\right]\right)$ are needed. Further, the approach should be tested against a variety of hydro-climatic conditions and different manifestations of climatic variations. Therefore, we have chosen the dataset of the model parameter estimation experiment (MOPEX) (Schaake et al., 2006), covering the United States. The dataset (available at: ftp://hydrology.nws. noaa.gov/pub/gcip/mopex/US_Data/) covers 431 basins distributed over different humid to arid climate types within the continental US. The good coverage allows to describe the hydro-climatic state at a regional and continental scale of the US. A range of hydro-climatic and ecohydrological studies already used this dataset, e.g. Oudin et al. (2008); Troch et al. (2009); Wang and Hejazi (2011); Voepel et al. (2011). The catchment area of the basins ranges from 67 to $10329 \mathrm{~km}^{2}$ with a median size of $2152 \mathrm{~km}^{2}$.

The dataset contains daily data of $P, Q$, daily minimum $T_{\min }$ and maximum temperature $T_{\max }$ as well as a climatologic potential evapotranspiration estimate $\left(E_{\mathrm{p}, \mathrm{clim}}\right)$, which is based on pan evaporation data of the period 1956-1970 (Farnsworth and Thompson, 1982). Because a time series of annual $E_{\mathrm{p}}$ is needed, we considered two temperaturebased $E_{\mathrm{p}}$ formulations (Hargreaves and Hamon) and one $E_{\mathrm{p}}$ product (CRU TS 3.1) being a modification of the PenmanMonteith method.

The temperature-based formulations are attractive as these allow a computation of $E_{\mathrm{p}}$ from the available data in the MOPEX dataset. The Hargreaves equation (Hargreaves et al., $1985)$ can be used to estimate daily $E_{\mathrm{p}}$ :

$E_{\mathrm{p}, \text { Hargreaves }}=a \cdot \operatorname{sd}_{\mathrm{pot}}\left(\left(T_{\max }-T_{\min }\right) / 2+b\right) \cdot \sqrt{T_{\max }-T_{\min }}$,

where $\operatorname{sd}_{\text {pot }}$ is the maximal possible sunshine duration of a given day at given latitude and two empirical parameters ( $a=0.0023, b=17.8$ ). It has minimal data requirements ( $T_{\min }$ and $T_{\max }$ ), but yields a good agreement with physically based $E_{\mathrm{p}}$ models (Hargreaves and Allen, 2003; Aguilar and Polo, 2011). Potential evapotranspiration by Hamon equation (Hamon, 1963) depends on daily average temperature $(T)$ and daytime length $\left(L_{\mathrm{d}}\right)$ only (Lu et al., 2005):

$E_{\mathrm{p}, \text { Hamon }}= \begin{cases}1.9812 \cdot L_{\mathrm{d}} \cdot \rho_{\mathrm{sat}}(T) \cdot k & \text { if } T>0^{\circ} \mathrm{C} \\ 0 & \text { if } T<0^{\circ} \mathrm{C}\end{cases}$

Thereby, the saturated vapour density is $\rho_{\text {sat }}(T)=216.7$. $e_{\text {sat }} /(T+273.3)\left[\mathrm{g} \mathrm{m}^{-3}\right]$, with the saturated vapour pressure being $e_{\text {sat }}=6.108 \cdot \exp (17.26939 \cdot T /(T+237.3))[\mathrm{mb}]$. The calibration parameter $k$ was set to 1.2 in accordance with $\mathrm{Lu}$ et al. (2005). Both methods have been tested in previous studies, mostly comparing $E_{\mathrm{p}}$ estimates with Penman estimates for selected weather stations, e.g. Amatya et al. (1995). Lu et al. (2005) found, by comparing $E_{\mathrm{p}}$ formulations at the annual time scale for watersheds in the south-east of the US, that the Hargreaves method yields the most extreme estimates, while the Hamon equation showed the most reasonable results under the temperature-based methods.

Radiation-based formulations are more difficult to derive for the domain and the period considered in this paper. However, the Climatic Research Unit (CRU), University of East Anglia, established a globally available gridded dataset $\left(0.5^{\circ}\right)$ of monthly $E_{\mathrm{p}}$, which is based on the FAO (Food and Agricultural Organization) grass reference evapotranspiration method (Allen et al., 1994). Essentially, these estimates are based on observed and spatially interpolated data (Mitchell and Jones, 2005) of temperature (mean, minimum, maximum), vapour pressure and cloud cover. Here, we used monthly data from http://www.cgiar-csi.org/component/k2/ item/104-cru-ts-31-climate-database and extracted basin average values (using the $\mathrm{R}$ function raster::extract, Hijmans and van Etten, 2012).

Finally, all daily data, i.e. $\left(P, E_{\mathrm{p}}, Q\right)$, are aggregated to annual sums for water years defined from 1 October30 September. The final dataset covers the period 1949 to 2003 with 430 basin series.

\section{Results and discussion}

\subsection{Hydro-climate conditions in the US}

The basins in the US MOPEX dataset cover a variety of hydro-climatic conditions, which can be seen in the mapping of long-term average variables $\left(P, Q, E_{\mathrm{p}, \mathrm{clim}}, E_{\mathrm{p}, \mathrm{CRU}}\right)$ in Fig. 1. The basins with most precipitation are found in the Northwest, the Southeast and along the east coast. The central part of the US receives considerably less precipitation, which is a continental climate effect intensified by the mountain ranges in the west and east, blocking west to east atmospheric moisture transport. Potential evapotranspiration obeys a north to south increasing gradient, which is modulated by the continental climate in the central US. The bottom maps show the climatological $E_{\mathrm{p}}$ estimates from the evaporation atlas (Farnsworth and Thompson, 1982) and the long-term averages of the CRU TS 3.1 potential evapotranspiration estimates $E_{\mathrm{p}, \mathrm{CRU}}$. The long-term basin averages of $E_{\mathrm{p}, \mathrm{CRU}}$ show the highest spatial correlation ( $\left.r=0.89\right)$ to $E_{\mathrm{p}, \mathrm{clim}}$, while Hamon $(r=0.57)$ and Hargreaves $(r=0.46)$ have lower correlation and somewhat different spatial patterns. Therefore, we selected $E_{\mathrm{p}, \mathrm{CRU}}$ for further analysis.

Streamflow is naturally governed by precipitation input and follows the spatial patterns of precipitation. However, the arid conditions in the central US result in lower streamflow amounts. This functional dependency can be seen in the Budyko plot in the left panel of Fig. 2, plotting the evaporation ratio $E_{\mathrm{T}} / P$ as function of the aridity index $E_{\mathrm{p}} / P$. In general, the basins follow the Budyko hypothesis, whereby 

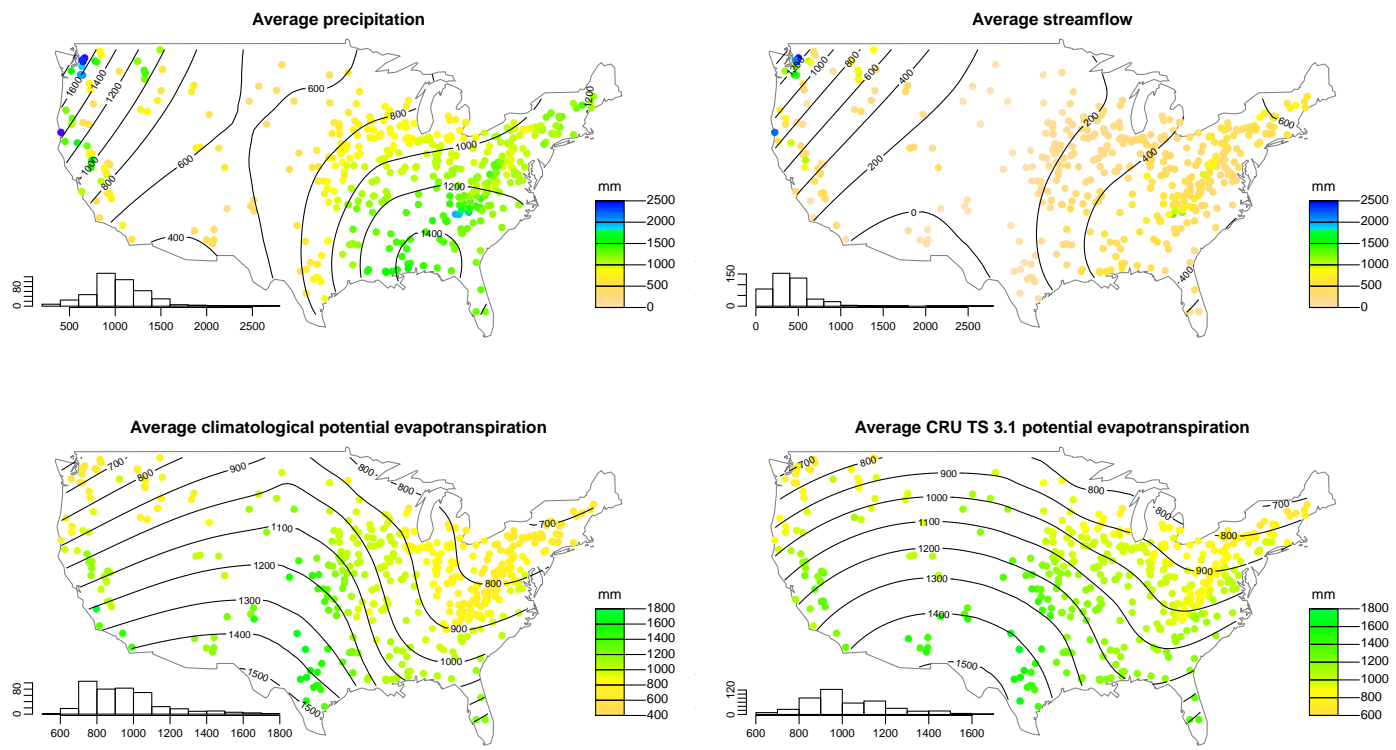

Fig. 1. Long-term annual average of hydroclimatic variables of the US MOPEX dataset (1949-2003). The contour lines are derived from fitted polynomial surfaces using the $\mathrm{R}$ function stats::loess (R Development Core Team, 2011) of the variables using the river gauge locations. The map of the US is taken from the maps package (Becker et al., 2011).
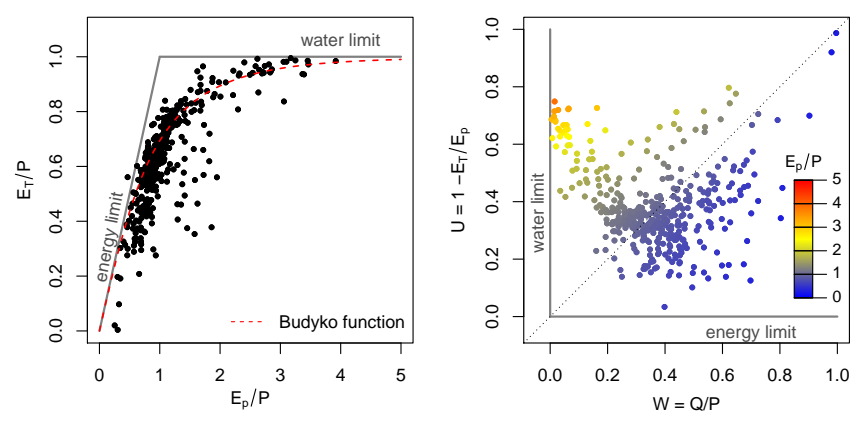

Fig. 2. Budyko (left) and $U W$ space (right) plots of the period (1949-2003) of the MOPEX dataset. $E_{\mathrm{p}}$ is obtained from the CRU TS $3.1 E_{\mathrm{p}}$ product. The $1: 1$ line in the $U W$ space diagram separates areas with energy limitation $\left(E_{\mathrm{p}} / P<1\right)$ and water limitation $\left(E_{\mathrm{p}} / P>1\right)$. Grey lines indicate the water and energy limits.

Budyko's function explains $69 \%$ of the variance. The aridity index $E_{\mathrm{p}} / P$ of the basins ranges between 0.25 and 5.52 , with most basins clustering around 1 . The right panel of Fig. 2 displays the relationship of the non-dimensional measures $W$ and $U$, referred to as UW space. Note that $W=1-\frac{E_{\mathrm{T}}}{P}$, whereby $E_{\mathrm{T}} / P$ is used in the Budyko plot on the ordinate. A thorough discussion of the relationship between both spaces can be found in Renner et al. (2012). The hydro-climatic data cover the UW space, meaning that there is a large variety of hydro-climate conditions in the dataset. $W$ is ranging between 0 and 1, while $U$ also has one negative value (not shown because of the scales used for the axes). This is probably due to an underestimation of $E_{\mathrm{p}, \mathrm{CRU}}$ for this basin.

\subsection{Climate sensitivity of streamflow}

Next, we compare the climate sensitivity coefficients of the CCUW with the Budyko framework using the long-term averages of the MOPEX dataset. In particular, we concentrate on the sensitivity of streamflow to precipitation $\varepsilon_{Q, P}$.

Using the CCUW approach, $\varepsilon_{Q, P} ;$ CCUW is determined by Eq. (4), which shows that the coefficient is dependent on the aridity index and the inverse of the runoff ratio. In particular, the correlation of the sensitivity coefficient to the aridity index (correlation $r=0.53$ ) is much lower than the correlation to $P / Q(r=0.99)$. This means that, using the CCUW hypothesis, the inverse of the runoff ratio $(P / Q)$ is the main controlling factor in determining runoff sensitivity to climate.

To further illustrate this functional relationship, we plot $\varepsilon_{Q, P}$ in Fig. 3 as a function of the evaporation ratio, which is directly related to the inverse of the runoff ratio, but bounded between 0 and 1 . From the left panel (black dots), we see that the estimate of the CCUW method $\left(\varepsilon_{Q}, P\right.$; CCUW $)$ is primarily and nonlinearly determined by $E_{\mathrm{T}} / P$. To estimate the uncertainty in estimation of $\varepsilon_{Q, P} ; \mathrm{CCUW}$, we computed $\varepsilon_{Q, P ; \mathrm{CCUW}}$ for each year in the 55-yr period and display the interquartile range ( $25 \%-75 \%$ percentile range) of all those annual sensitivity coefficients as vertical grey lines. The uncertainty ranges increase with $E_{\mathrm{T}} / P$. For values of $E_{\mathrm{T}} / P>0.6$, the ranges get more apparent with about $25 \%$ of $\varepsilon_{Q, P}$, which can be up to the order of $\varepsilon_{Q, P}$ for $E_{\mathrm{T}} / P>0.8$. This implies, the smaller the runoff ratio of a given basin, the larger is the sensitivity to climate variations and the uncertainty in its estimation. Moreover, the variability in climatic forcing 

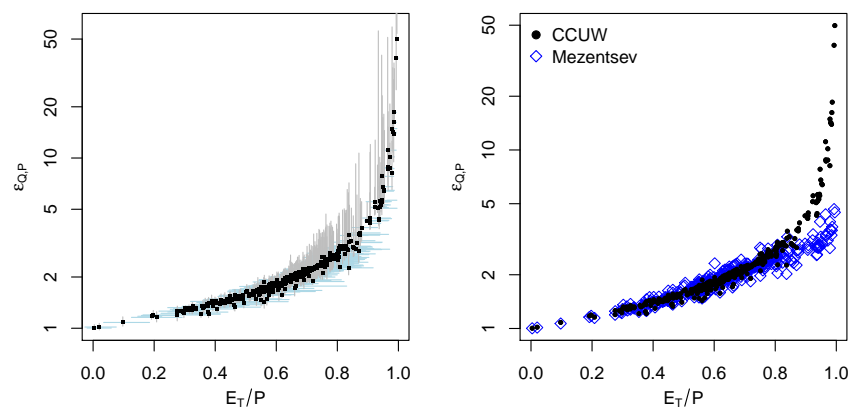

Fig. 3. Sensitivity coefficients of streamflow to precipitation as function of $E_{\mathrm{T}} / P$. Left panel: $\varepsilon_{Q}, P$;CCUW computed for the CCUW method. Dots represent $\varepsilon_{Q}, P$; CCUW using long-term average data of the respective basin. Vertical grey lines depict the interquartile range of $\varepsilon_{Q, P}$;CCUW estimated for each year in the record, while light blue horizontal lines show the interquartile range for $E_{\mathrm{T}} / P$. Right panel: $\varepsilon_{Q, P}$ for different methods using long-term averages of $\left(P, E_{\mathrm{p}}, Q\right)$ of the period 1949-2003. Note that a logarithmic y-axis is used for both plots.

of individual years or periods can have large impacts on the resulting streamflow.

The right panel of Fig. 3 provides a comparison of the sensitivity estimates of CCUW with the parametric Budyko function approach of Roderick and Farquhar (2011) using the Mezentsev function, with $n$ estimated for each basin separately. The non-parametric Budyko sensitivity approaches are determined by aridity only (Arora, 2002) and have large differences to CCUW, already at medium values of $E_{\mathrm{T}} / P$ (not shown). The parametric Budyko function approach yields similar sensitivities as the CCUW approach for $E_{\mathrm{T}} / P<0.9$. This is due to the parameter $n$, which inherently includes some dependency to $E_{\mathrm{T}} / P$ (the correlation of $\varepsilon_{Q, P ; \text { Mez }}$ to $P / Q$ is $r=0.63$ ). However, it can be shown that there is an upper limit for the sensitivity coefficient, which is set by $n+1$. Here, we estimated the largest value of $n$ for the given dataset with $n=4$ and the largest sensitivity with $\varepsilon_{Q, P, \mathrm{Mez}}=4.7$. In contrast, the sensitivity of streamflow to precipitation estimated by the CCUW approach is not bounded and proportional to the inverse of the runoff ratio. However, the theoretical assessment of the CCUW hypothesis by Renner et al. (2012) revealed that these large streamflow sensitivity estimates for strongly water-limited basins are probably incorrect, because the CCUW does not obey Budyko's water limit.

\subsection{Assessment of observed and predicted changes in streamflow}

Next, we evaluate the introduced analytical streamflow change prediction methods under past hydro-climatic changes in the contiguous US using data covering the water years from 1949 to 2003. As the approaches assume steady-state conditions, we evaluate the changes by subdividing the data into two periods, 1949-1970 and 1971-2003.
Table 1. Statistics of the average change of the three $E_{\mathrm{p}}$ estimates. The first three columns depict quantiles of $\Delta E_{\mathrm{p}}$; the forth and fifth columns denote the relative frequency of basins with significant change ( $\alpha=0.05$, two sample t-test) for $E_{\mathrm{p}}$ and the aridity index (AR).

\begin{tabular}{lrrrrr}
\hline & $\begin{array}{r}10 \% \\
{[\mathrm{~mm}]}\end{array}$ & $\begin{array}{r}50 \% \\
{[\mathrm{~mm}]}\end{array}$ & $\begin{array}{r}90 \% \\
{[\mathrm{~mm}]}\end{array}$ & $\Delta E_{\mathrm{p}} \leq \alpha$ & $\Delta \mathrm{AR} \leq \alpha$ \\
{$[\%]$} & {$[\%]$} \\
\hline CRU & -32 & -8 & 13 & 13 & 19 \\
Hargreaves & -41 & -23 & -6 & 69 & 40 \\
Hamon & -16 & -6 & 9 & 6 & 26 \\
\hline
\end{tabular}

This choice is in accordance with the recent study of Wang and Hejazi (2011). They justify their selection with a probable step increase in precipitation and in streamflow in large parts of the US around the year 1970 (McCabe and Wolock, 2002).

\subsubsection{Hydro-climatic changes in the US}

We describe the climatic changes by comparing long-term average data of the two periods 1949-1970 and 1971-2003. Analysing the difference of the average annual rainfall, we find an increase in $P$ for most basins, whereby the increase is significant for $32 \%$ of the basins $(\alpha=0.05$, Welch twosample t-test with unknown variance, using the function stats::t.test in R (R Development Core Team, 2011)). The top left map in Fig. 4 displays the spatial distribution of changes in $P$, which are largest over the Mississippi River basin (>90 mm, excluding the Missouri River basin). Significant changes in precipitation are scattered over parts of the Mississippi basin and in the Northeast. However, there are hardly any significant changes in the peninsula of Florida and the west. The drastic increase in precipitation has already been discussed in many publications, e.g. Lettenmaier et al. (1994); Milly and Dunne (2001); Krakauer and Fung (2008).

The assessment of changes in potential evapotranspiration necessarily depends on the method of choice and thus the input data, which can influence magnitude and even the sign of these trends (Donohue et al., 2010). A summary of changes for each $E_{\mathrm{p}}$ method is given in Table 1 . In general, there is a negative trend at more than $50 \%$ of the basins. The Hargreaves method yields the strongest trends and shows a much larger number of basins with a significant change in $E_{\mathrm{p}}$ and, to a lesser degree, also in the change of the aridity index. The correlation matrix of average changes in several variables (given in Table 2) shows that this trend in Hargreaves $E_{\mathrm{p}}$ is directly related to a decrease in the diurnal temperature range $\Delta \mathrm{TR}$, which has also been reported by Lettenmaier et al. (1994). The $E_{\mathrm{p}}$ changes by the Hamon and CRU product are smaller and less significant. Changes in the Hamon equation are directly and positively related to changes in average temperature $\Delta T$ (cf. Table 2). Changes in the $E_{\mathrm{p}, \mathrm{CRU}}$ product are positively related to changes, both in average 

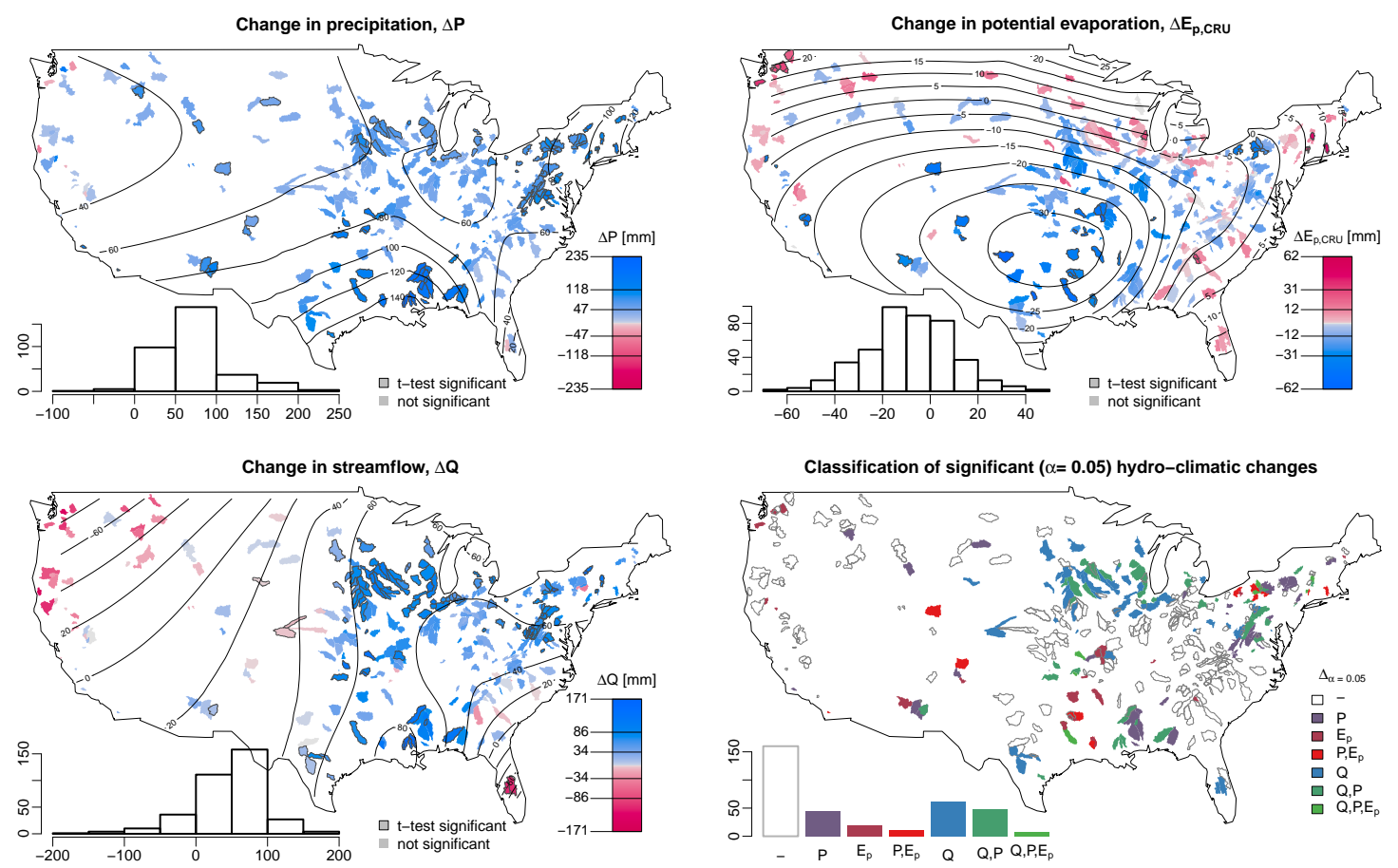

Fig. 4. Maps of absolute change in hydro-climatic variables of the MOPEX dataset, comparing changes between the periods 1949-1970 and 1971-2003. Annual changes are given in millimeter. Significant changes in the mean of both periods are tested by univariate two-sample t-tests with $\alpha=0.05$ and are denoted by a grey borderline. For each variable, a histogram of the changes is given in the lower left corner. The map in panel (d) provides a classification based on the univariate t-tests.

Table 2. Pearson correlation coefficients for the average change between the two periods, assessed for all basins with data available. Significance of correlation is denoted with letters $\left({ }^{\mathrm{a}} 0.001,{ }^{\mathrm{b}} 0.01,{ }^{\mathrm{c}} 0.05\right)$, with significant correlations $(\alpha<0.05)$ set in bold for visual aid.

\begin{tabular}{lrrrrrr}
\hline & $\Delta Q$ & $\Delta P$ & $\Delta E_{P, \mathrm{CRU}}$ & $\Delta E_{P, \mathrm{HAR}}$ & $\Delta E_{P, \mathrm{HAM}}$ & $\Delta T$ \\
\hline$\Delta Q$ & & & & & & \\
$\Delta P$ & $\mathbf{0 . 5 7}^{\mathrm{a}}$ & & & & & \\
$\Delta E_{\mathrm{P}, \mathrm{CRU}}$ & $-\mathbf{- 0 . 1 8}^{\mathrm{a}}$ & $-\mathbf{0 . 1 7}$ & & & & \\
$\Delta E_{\mathrm{P}, \mathrm{HAR}}$ & $-\mathbf{0 . 1 3}$ & -0.01 & 0.08 & & & \\
$\Delta E_{\mathrm{P}, \mathrm{HAM}}$ & $-\mathbf{- 0 . 2 3}^{\mathrm{a}}$ & $-\mathbf{0 . 2 3}$ & $\mathbf{0 . 3 0}^{\mathrm{a}}$ & -0.04 & & \\
$\Delta T$ & $-\mathbf{0 . 2 2}^{\mathrm{a}}$ & $-\mathbf{0 . 1 9}^{\mathrm{a}}$ & $\mathbf{0 . 2 4}^{\mathrm{a}}$ & 0.01 & $\mathbf{0 . 9 6}^{\mathrm{a}}$ & \\
$\Delta \mathrm{TR}$ & $-\mathbf{0 . 1 8}^{\mathrm{a}}$ & -0.01 & $\mathbf{0 . 1 3}^{\mathrm{b}}$ & $\mathbf{0 . 9 9}^{\mathrm{a}}$ & -0.02 & 0.02 \\
\hline
\end{tabular}

temperature and diurnal temperature range (Table 2). This finding further supports the usage of the CRU $E_{\mathrm{p}}$ dataset. The top right map of Fig. 4 shows that negative significant changes in average $E_{\mathrm{p}}$ are common in the southern central parts (about $-30 \mathrm{~mm}$ ) and a few patches throughout the US.

Both the increase in precipitation and the decrease in potential evapotranspiration should ideally lead to an increase in annual streamflow. This is supported by the strong positive correlation with precipitation changes and the negative correlation coefficients with the $E_{\mathrm{p}}$ changes (Table 2). Further, we find that $32 \%$ of the basins show a significant increase. The map in the bottom left panel of Fig. 4 shows that basins with significant increases in streamflow are predominantly found within the Upper Mississippi River basin and the northern Appalachian Mountains and a few basins on the southern coast. These basins show an increase of about $41 \%$ compared to the average of the first period. For most of the other regions, we find non-significant streamflow increases, while in the west there are mainly non-significant declines in annual streamflow. Please note that we only use basins for further analysis, which have more than $10 \mathrm{yr}$ of data in any of the two periods and that we removed 2 basins, because the water balance was suspect $(Q>P)$. So in total 351 basins are kept for further analysis. 

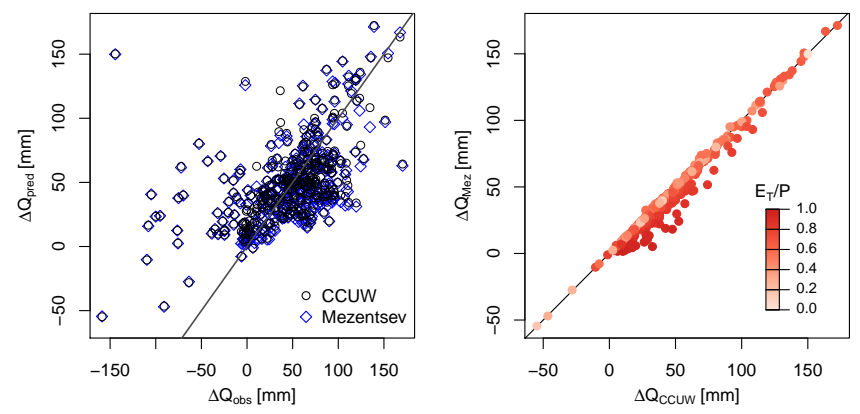

Fig. 5. Left: Scatterplot of observed vs. predicted annual average changes in streamflow for MOPEX dataset without stations with missing data. The vertical difference to the $1: 1$ line depicts the deviation of the prediction to the observed value. Right: predicted change in streamflow due to climatic changes, comparing the estimates of the Budyko framework with the CCUW estimates. The colour of the dots represents the evaporation ratio $E_{\mathrm{T}} / P$.

\subsubsection{Evaluation of streamflow change predictions}

In the previous subsection, we described the changes observed in precipitation, potential evapotranspiration and streamflow by comparing the long-term averages of two periods. Now we aim to predict the change in streamflow, using the climate sensitivity approaches of the CCUW method (i.e. application of Eq. 5) and the Budyko approach illustrated by Roderick and Farquhar (2011). For the Budyko approach, we use Eq. (8) and the functional form of Mezentsev (1955). In particular, we use the hydro-climatic state of the first period, described by $P_{0}, E_{\mathrm{p}, 0}, Q_{0}$, as well as the climatic states of the second period $P_{1}, E_{\mathrm{p}, 1}$ to predict the streamflow of the second period $Q_{1}$. Then, we evaluate the accuracy of streamflow prediction by using the observed $\Delta Q_{\mathrm{obs}}$ and predicted change $\Delta Q_{\text {clim }}$ signals.

A scatterplot of predicted versus observed changes is shown in the left panel of Fig. 5, where dots close to the $1: 1$ line indicate good predictions. While most dots scatter around the $1: 1$ line, there is a considerable number of basins where prediction and observation are completely different. There is also no indication if one method is more realistic than the other. Based on all basins $(N=$ 351 ), both methods yield similar differences compared with the observed change in streamflow $\left(\mathrm{RMSE}_{\mathrm{CCUW}}=40.9 \mathrm{~mm}\right.$, $\mathrm{RMSE}_{\mathrm{Mez}}=41.3 \mathrm{~mm}$ ). A direct comparison is shown as scatterplot in the right panel of Fig. 5. The graph indicates that there is a general agreement between both estimates $(r=0.99)$. The largest differences between both methods are found for basins with very high evaporation ratios. In this case, CCUW predicts larger changes than the Budyko approach, which was already discussed above. These changes are small in absolute values, but quite large when seen relative to the annual totals of streamflow.

\subsubsection{Separating the influence of climate and land-use impacts on streamflow}

From the maps in Fig. 4, it is apparent that basins with significant changes in streamflow do not necessarily match with those having significant changes in the climatic variables $\left(P, E_{\mathrm{p}}\right)$. Such inconsistency between climatic and streamflow trends was also reported in previous literature such as in Lettenmaier et al. (1994).

For further analysis, we combined the results of the univariate t-tests $(\alpha=0.05)$, which resulted in 9 different classes. These are further aggregated to the four different hypotheses on streamflow change elaborated in Sect. 2.4. In Table 3, we provide summary statistics for each class. The map in Fig. 4d shows the location of the groups in the US, with a bar plot in the lower left corner showing the counts of each group. For most basins (46\%), we found no significant change in any of the three observed variables. The group of basins where only streamflow changed significantly while climatic variables show insignificant changes is large and consists of $17 \%$ of all basins. These are mostly found in the central north of the US, west of the Great Lakes. In the other extreme, there are basins, where significant climatic changes occurred, while streamflow did not change significantly. Combining these classes to the "climate only" group, $21 \%$ of the basins are affected. For this group, reddish colours have been used in the map in Fig. 4d. This group is dominant in the west and shows some clusters in the South- and Northeast. Coloured in shades of green, the smallest groups are those where at least $Q$ and $P$ changed significantly. Adding up these groups to the "climate \& runoff" change group comprises $16 \%$ of the basins.

The differences between observed and predicted streamflow changes may be due to model deficiencies or input data uncertainty only. In this case, we would expect that the differences are distributed randomly in the set of basins. However, if we take basin changes as alternative hypotheses into account ("climate only", "runoff only"), we would expect that the differences are not random, but carry typical signals of basin change impacts being different from zero.

To investigate this, we analysed the differences normalised by annual average precipitation for the classes of basins determined by the combined t-tests. Results are shown for the four main classes in Table 3 and in the boxplot in Fig. 6. In the "no change" group, we find a large scatter with the median close to 0 and the interquartile ranges below and above 0 , indicating that there is no general trend in the model differences. This behaviour is expected because there are no large and significant changes in the hydro-climate of these basins. The other basins are more interesting. The group of basins where we found significant "climate only" changes shows that most of the basins in this group are below 0 . For this group, the Budyko framework has an average difference of $-2.1 \%$ and CCUW $-2.7 \%$ of the annual water balance. This means that basin changes compensate for the 
Table 3. Group average statistics of hydro-climatic changes for 4 groups of basins ("no change", "climate only", "runoff only" and "climate $\&$ runoff"), classified by results of a combination of two-sample t-test results grouping basins with significant change at $\alpha=0.05$. For the hydro-climatic changes, also the group standard deviation is given. For the normalised basin changes, the first and third quartiles are given. In total 351 basins have been tested.

\begin{tabular}{llrrrr}
\hline & Unit & No change & Climate only & Climate \& runoff & Runoff only \\
\hline $\mathrm{N}$ & - & 160 & 75 & 55 & 61 \\
$E_{\mathrm{p}} / P$ & - & 1.15 & 1.22 & 1.10 & 1.28 \\
$\Delta P$ & $\mathrm{~mm}$ & $50 \pm 24$ & $97 \pm 43$ & $113 \pm 42$ & $61 \pm 21$ \\
$\Delta E_{\mathrm{P}}$ & $\mathrm{mm}$ & $-8 \pm 14$ & $-13 \pm 23$ & $-8 \pm 18$ & $-7 \pm 12$ \\
$\Delta Q$ & $\mathrm{~mm}$ & $23 \pm 41$ & $44 \pm 45$ & $95 \pm 31$ & $67 \pm 43$ \\
$\omega_{\mathrm{obs}}$ & $\circ$ & 300 & 286 & 337 & 2 \\
$\Delta C_{\mathrm{E}}$ & - & 0.02 & 0.05 & -0.04 & -0.06 \\
$\Delta n$ & - & 0.05 & 0.15 & -0.12 & -0.15 \\
$\mathrm{RMSE}$ & $\mathrm{mm}$ & 37.98 & 49.22 & 31.89 & 43.94 \\
$\mathrm{RMSE}$ & 37.70 & 48.18 & 34.57 & 46.22 \\
$\Delta Q_{\text {basin,CCUW }} / P$ & - & $-0.03-0.01$ & $-0.04-0$ & $-0.01-0.05$ & $0.02-0.06$ \\
$\Delta Q_{\text {basin,Mez }} / P$ & - & $-0.02-0.01$ & $-0.03-0$ & $0-0.05$ & $0.02-0.06$ \\
$\Delta Q_{\text {basin,CCUW }} / Q$ & - & $-0.08-0.03$ & $-0.12--0.01$ & $-0.01-0.19$ & $0.05-0.27$ \\
$\Delta Q_{\text {basin, Mez }} / Q$ & - & $-0.07-0.05$ & $-0.1-0$ & $0-0.24$ & $0.06-0.29$ \\
\hline
\end{tabular}

detected climatic changes (with a group average decrease in aridity of $-10.2 \%$ ). Further analysis shows that $E_{\mathrm{T}}$ strongly increased with $6.2 \%$ of the annual water balance. Also the catchment parameter $n$ and $C_{\mathrm{E}}$ show significant increases (cf. Table 3). In contrast, the "runoff only" group shows significant positive basin change impacts (Budyko $3.8 \%$ and CCUW $3.2 \%$ of the annual water balance). In these basins, we find predominant increases in streamflow, along with significantly decreasing catchment parameters. This indicates that changes in the basin properties took place, which led to predominant runoff increases ( $7.7 \%$ of the water balance) on similar magnitude of the group average precipitation increase $(7.3 \%)$. Thus, on average, the increase in precipitation did not increase $E_{\mathrm{T}}(-0.4 \%$ of the water balance).

The "climate \& runoff" change group reveals smaller errors; however, most of these tend to be influenced by basin changes with positive differences. The map in Fig. $4 \mathrm{~d}$ displaying the location of the groups shows that many of these basins are actually close to the "runoff only" group and so we expect that basin changes are quite likely.

The ecohydrological framework of Tomer and Schilling (2009) is based on analysing changes in the relative partitioning of the surface water and energy fluxes. In Fig. 7, we plot the observed changes, i.e. $\Delta U$ vs. $\Delta W$, using data of all MOPEX basins. From the figure, it becomes apparent that most of the basins shifted towards the right of the positive diagonal, which is an effect of the general trend of increasing humidity (increasing $P$ and widely decreasing $E_{\mathrm{p}}$ ) over the US. The differences of the predicted changes to the observed changes in streamflow are depicted by the size of the dots and the colour palette. Generally, the smallest deviations are found in the lower right quadrant, which represents the climate impact change direction of the ecohydrological concept. Towards the upper right quadrant, we find that basin impacts are increasing, leading to an excess of streamflow, while towards the lower left quadrant basin impacts show compensating effects leading to streamflow deficits.

In the right panel of Fig. 7, we use the plotting characters corresponding to the t-test classification groups. Most basins in the "runoff only" group are in the upper right quadrant, while the "climate only" group is concentrated in the lower two quadrants and predominant $\Delta U$ increases. So, although the concept of Tomer and Schilling has certain limitations such as the dependency to the aridity index and the hydrological response (Renner et al., 2012), it is generally able to separate the basin and climate impacts on $E_{\mathrm{T}}$ and streamflow.

In summary, the analysis shows that the differences $\Delta Q_{\text {obs }}-\Delta Q_{\text {clim }}$ are unlikely to be random and due to model deficiencies, but rather reveal distinctive impacts of basin changes under the general trend of increasing humidity. Further, frequency and impacts of basin changes are large and evidently much larger than the differences between both frameworks.

\subsubsection{Change direction in UW space}

For further analysis, we concentrate on the direction of change in the UW space $\omega$, introduced with Eq. (3), which approximately yields a measure of the relative impact of both climatic and basin changes. Graphically, $\omega$ represents the angle between the positive $\mathrm{x}$-axis and some point in a $\Delta U$ vs. $\Delta W$ plot, such as Fig. 7. As a reference, we computed the theoretical change direction of climatic changes using the Budyko framework with the Mezentsev curve being dependent on the aridity index and the catchment parameter $n$. In the scatter plots of Fig. 8, we plot the observed change direction $\omega_{\mathrm{obs}}$ as a function of the theoretical climate change 
Normalised basin change impact subset by change classification $(\alpha=0.05)$

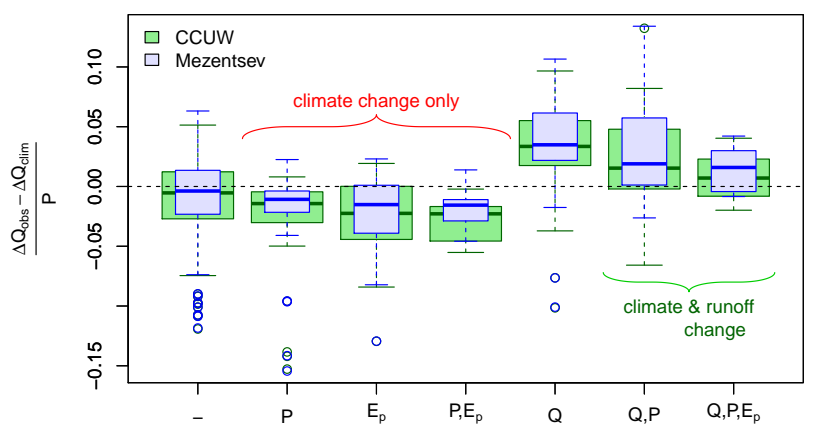

Fig. 6. Boxplot of the difference of observed and predicted annual average changes in streamflow normalised by annual average of precipitation of the first period. Subsets are in accordance with the t-test classification.

direction $\omega_{\mathrm{Mez}}$. If we assume that there are only changes in climate which impact streamflow, we would find all points at the $1: 1$ line. We also show the climate change direction of the CCUW hypothesis, which is constant at $315^{\circ}$. Any deviations from these lines indicate the concurrence of basin changes, assuming the models and input data are correct. The size and colour of the dots correspond to the magnitude of normalised difference to the observed change in runoff. We find that there is a clear relation between $\omega_{\text {obs }}$ and the normalised difference, which is positive above the $1: 1$ line and negative below. The largest differences and thus impacts occur at $\omega_{\mathrm{obs}} \approx 225^{\circ}$ when both $n$ and $C_{\mathrm{E}}$ increase strongly, whereas at $\omega_{\mathrm{obs}} \approx 45^{\circ}, n$ and $C_{\mathrm{E}}$ decrease strongly. This is confirmed by the scatterplot in the right panel, where the plotting character corresponds to the statistical classification of the basins. Most "climate only" basins are below the $1: 1$ line, while "runoff only" basins are found mainly above. Also note that the "climate \& runoff" group has quite a few basins far above the $1: 1$ line.

The combination with the independent classification shows that in general both frameworks seem to be valid for predicting climate change impacts and separating them from basin change impacts. Also the differences between both approaches are generally relatively small. However, very interesting is the performance under limiting conditions, where larger differences must become apparent. Unfortunately, the MOPEX dataset has not too many arid or humid basins and inferences are rather limited. In the left panel of Fig. 8, we also depict isolines of the aridity index of the respective basins, where arid basins have a lower $\omega_{\mathrm{Mez}}$ than more humid ones. We see that arid basins with significant changes follow the $1: 1$ line, rather than the $\omega_{\mathrm{CCUW}}=315^{\circ}$ line. This supports the validity of the Budyko framework and suggests that the CCUW is not valid under arid conditions.

The theoretical climate change direction reflecting the aridity index and the catchment parameter is mapped in the left panel of Fig. 9. This reveals how the actual
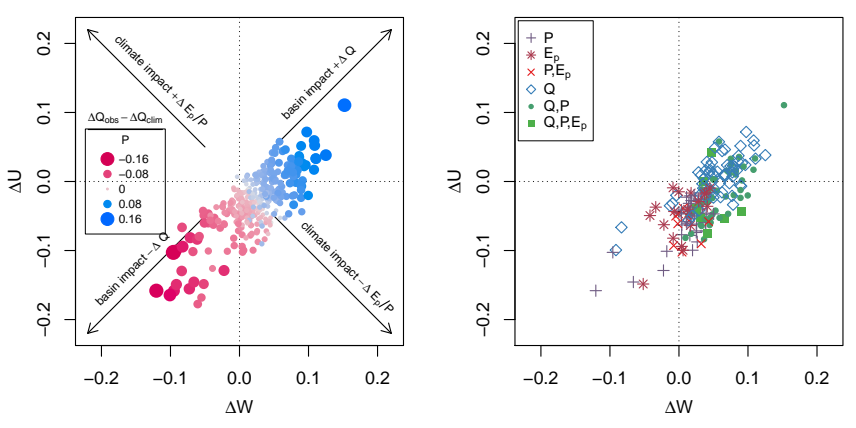

Fig. 7. Observed changes in UW space between the two periods. The arrows represent the conceptual framework of Tomer and Schilling (2009) to separate climate and basin change impacts. Changes falling approximately below the positive diagonal are related to a decrease in aridity. Under a general trend of decreasing aridity, basin changes leading to an increase of the runoff ratio are approximately above the negative diagonal, while basin changes compensating for climatic impacts are below. In the left panel, the size and colour of the dots depict the normalised difference between observed and climatic related streamflow change. The right panel is restricted to basins with significant changes only, using the t-test classification scheme. Note that for displaying reasons we do not show the change for the Snoqualmie River near Carnation, Wash. In this northwestern river, streamflow dropped strongly, while precipitation increased slightly, which resulted in large changes in $\Delta W=-0.12$ and $\Delta U=-0.38$.
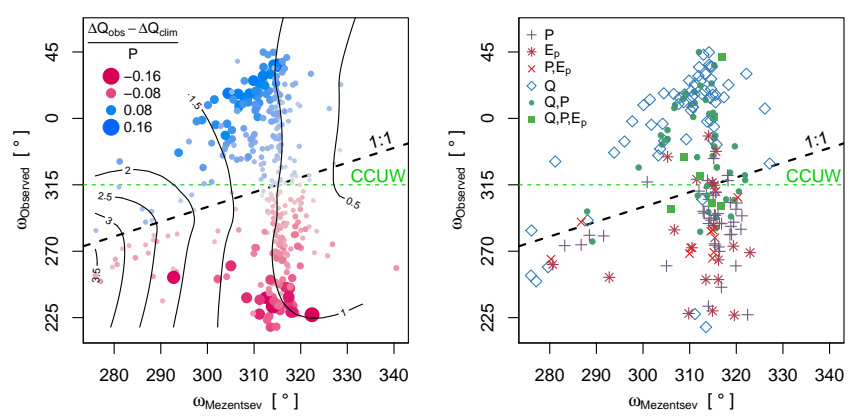

Fig. 8. Observed change direction in UW space $\omega=$ $\arctan (\Delta U / \Delta W)$ as a function of the theoretical change direction according to the Mezentsev function for all 351 MOPEX basins. In the left panel, the size and colour of the dots depict the normalised difference between observed and climatic related streamflow change. The right panel is restricted to basins with significant changes only, using the t-test classification scheme.

hydro-climatic conditions in the US modify relative changes in the partitioning of water and energy fluxes at the surface. Most basins have no water or energy limitation (aridity close to 1 ), and a climate change would equally alter the relative partitioning of water and energy fluxes (i.e. $\Delta U=-\Delta W \rightarrow$ $\omega \approx 135,315^{\circ}$ ), which is the assumption of the concept of Tomer and Schilling (2009) and the CCUW hypothesis. The more arid climate in the central US, however, results in much larger relative changes of the partitioning of energy fluxes 
Theoretical climatic change direction in UW space, Mezentsev

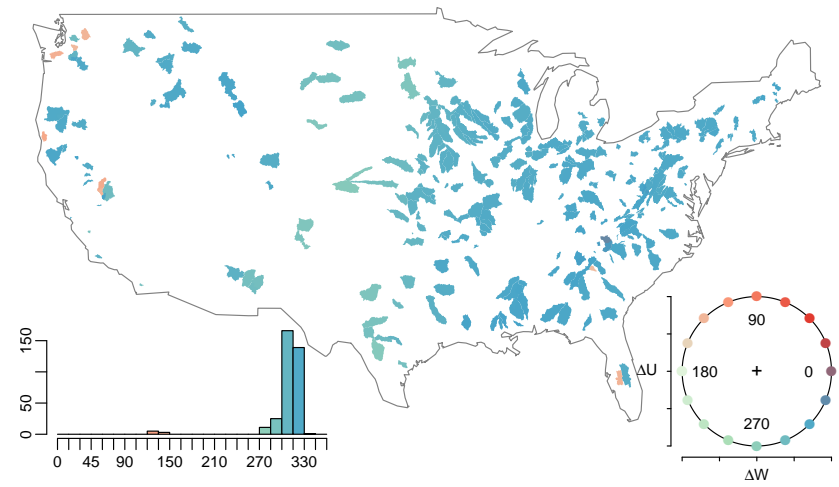

Observed climatic change direction in UW space

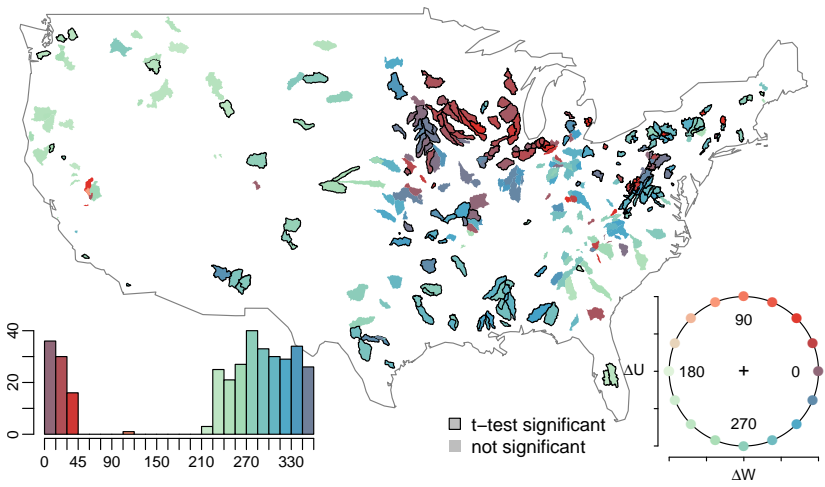

Fig. 9. Mapping of the change direction $\omega$ in UW space. The colour of the polygons indicates the value of $\omega$ with the corresponding wheel legend in the bottom right. The left panel shows the theoretical climatic change direction using the Mezentsev function. The right panel shows the observed change direction using Eq. (3). Polygons with a grey border indicate significant (t-test, $\alpha=0.05)$ changes in any of the observed variables $\left(P, E_{\mathrm{p}, \mathrm{CRU}}, Q\right)$.

than in the water fluxes $(|\Delta U|>|\Delta W|)$. This means that an increase in precipitation would decrease the normalised sensible heat flux much more than the runoff ratio would increase.

The mapping of $\omega_{\text {obs }}$ in the right panel of Fig. 9 provides a quick overview on climatic and basin change impacts. If we consider a segment of $45^{\circ}$ centred at $\omega_{\mathrm{Mez}}$, this would reflect roughly constant $n$ and valid conditions for the Budyko framework. About $29 \%$ of the basins are actually within this boundary. According to the map in Fig. 9, these basins are mainly found in the southern central part of the US, along a band following the Appalachian Mountains, and a few single basins in the west. Basins with distinct climate impacts and compensating basin effects with increasing $n$ and $C_{\mathrm{E}}$ $\left(\omega_{\mathrm{obs}}-\omega_{\mathrm{Mez}}<-22.5^{\circ}\right)$ are also quite frequent $(32 \%)$ and found throughout the US. Almost all basins within the Great Plains and the west show constant or decreasing runoff and increasing $E_{\mathrm{T}}$. This is in accordance with the findings of Walter et al. (2004), who detected positive trends in $E_{\mathrm{T}}$ but not in $Q$ for western river basins (Columbia, Colorado and Sacramento River basins). These trends may be linked to intraseasonal changes in hydrology, triggered by higher winter temperatures and thus less snow, which is melting earlier (Barnett et al., 2008). Moreover, groundwater pumping for irrigation in the High Plains (McGuire, 2009) possibly contributed to the observed signals (Kustu et al., 2010).

From the map in the right panel of Fig. 9, we see a transition of changes in $\omega_{\text {obs }}$ over the Mississippi River basin. While the western part shows $\omega_{\mathrm{obs}}<\omega_{\mathrm{Mez}}$, there is a strong transition towards the Midwest, where we find a large cluster of basins with $\omega_{\mathrm{obs}}>\omega_{\mathrm{Mez}}$. This transition may be primarily linked to the precipitation changes, which also show a west to east gradient (cf. map in Fig. 4). But agricultural cultivation, especially in basins of the US Midwest, may have amplified these trends. Most likely, the additional rain could not increase evapotranspiration as a lack of soil water storage due to intensive tile drainage (up to $30 \%$ of the total state areas in the Midwest are drained; Pavelis, 1987). So, the intensive agricultural land management did not only increase streamflow on average, but also led to immense nitrogen leaching of Midwestern soils (Dinnes et al., 2002), showing biochemical signals far downstream (Raymond et al., 2008; Turner and Rabalais, 1994).

Towards the east, changes in $\omega_{\text {obs }}$ are spatially more heterogeneous. This is probably because topography and land use are more diverse compared to the west. However, it is important to note that the density of river gauge records is much larger. The types of impacts are almost equally frequent, but as the maps of hydro-climatic changes already show, significant changes are rather concentrated in the north and south.

\subsection{Uncertainty discussion}

\subsubsection{Limitations due to observational data}

Both climatic sensitivity approaches are based on long-term average data. These input data are spatially aggregated to river basin averages from point data; evaporative demand and $E_{\mathrm{T}}$ are only indirectly observed. For example, Milly (1994) showed, by an uncertainty analysis of input data to their Budyko-based water balance model, that uncertainties in input data may explain the deviations from observed and modelled discharge and evapotranspiration.

Another issue is that net energy supply, i.e. net radiation data, is ideally required. However, direct observations of net radiation are not available for the purpose to estimate long-term catchment averages throughout the US. Therefore, a practical choice is to use potential evapotranspiration models, which provide an estimate based on available meteorological data. Here, we used two temperature-based $E_{\mathrm{p}}$ models: the Hargreaves equation being based on diurnal 
temperature ranges; and the Hamon equation, which is based on daily average temperatures. The results show that there are large differences on the long-term average as well as for the detected trends over time. So for example, we found that the changes in $E_{\mathrm{p}}$ derived with the Hargreaves equations are uncorrelated to the changes estimated by the Hamon equation or the $E_{\mathrm{p}}$ time series product of CRU (see Table 2). This is in accordance with previous studies on potential evapotranspiration models for hydrological applications. As, e.g., Donohue et al. (2010) note, the reliability of $E_{\mathrm{p}}$ estimates can be improved by adding more relevant input variables. Therefore, we used the $E_{\mathrm{p}}$ time series product of CRU, which includes humidity and cloudiness information. We find that this dataset is more consistent with respect to the long-term average and its spatial distribution as well as the temporal trends.

Still, there are certainly other reasons for the change in evaporative demand which are not reflected in the CRU $E_{\mathrm{p}}$ dataset - for example, changes in net long wave radiation as reported by Qian et al. (2007) or changes in the surface albedo due to land cover changes. While the latter can be attributed to basin characteristic changes, the former requires better high resolution radiation and energy balance estimates (Milly, 1994). These estimates may be available by using remote sensing products or reanalysis products for past periods. This is, however, out of the scope of this study.

Still, we believe that the main conclusions regarding the retrospective assessment of hydro-climatic changes and their regional patters will not be altered significantly by using improved data for evaporative demand. This is because the observed changes in the partitioning of water and surface fluxes can be attributed to a much larger part to the change in precipitation.

\subsubsection{Uncertainties due to inherent assumptions}

While introducing the theoretical framework by Renner et al. (2012) and the Budyko framework, considerable assumptions have been made that lead to uncertainties. First, we have to regard the assumption that the storages of water and energy are zero, which may be violated but hard to discern. For example, Tomer and Schilling (2009) used very dry periods to identify periods for computing long-term averages. However, this relatively subjective method may also introduce other problems. Secondly, we assume steady state conditions of the water and energy balances. Several processes may violate this assumption, resulting in a trend of $E_{\mathrm{T}}$ over time (Donohue et al., 2007). Our results clearly show that any process related to a change in basin characteristics may result in dynamic state transitions with impacts on evapotranspiration and thus streamflow, which can be larger than impacts of climatic variations. So we found that both catchment parameters $\left(n, C_{\mathrm{E}}\right)$ expressing the ability for evaporation have been widely increasing in the western US. This represents a non-stationary transition in the water and energy balances towards increasing actual evapotranspiration on the cost of streamflow. Thereby, the effects of climate and basin characteristic changes on streamflow seem to be of equal magnitude and compensate each other. In the companion paper, Renner et al. (2012), we discussed the different assumptions on catchment efficiency and climate changes. While the Budyko functions inherently assume that $C_{\mathrm{E}}$ is changing with the aridity index, the CCUW method assumes $C_{\mathrm{E}}$ to be constant. Here, we are unable to verify which assumption is correct because of the multitude of possible other effects, especially the large impacts of basin characteristic change. But we found that both frameworks yield comparable results under non-limited conditions, and both are generally able to discern climatic and different basin change impacts on streamflow. However, data of the few basins in arid conditions suggest that the CCUW sensitivity framework is unreliable under these generally water- limited conditions.

\section{Conclusions}

This paper presents an application and examination of two water-energy balance frameworks for the problem of estimating the sensitivity of streamflow to changes in long-term average precipitation and evaporative demand. In particular, we test and compare the CCUW framework with the Budyko framework by employing a large hydro-climatic dataset of the continental US, covering a variety of different climatic conditions (humid to arid) and basin characteristics, ranging from flat to mountainous basins with land cover types ranging from desert over agriculture to forested basins.

Based on long-term average hydro-climatological data $\left(P, E_{\mathrm{p}}, Q\right)$, we estimated the sensitivity of streamflow to changes in annual precipitation. The main distinction between the Budyko and the CCUW hypotheses is the functional dependency of the sensitivity coefficients. The sensitivity coefficients estimated by the Budyko framework depend on the aridity index and the type of the Budyko function only. In contrast, the CCUW hypothesis implies that climatic sensitivity of streamflow depends to a large degree on the inverse of the runoff ratio. This fundamental difference results in sizeable differences, which are most prominent for basins where runoff is very small compared to annual precipitation. However, for most of the other basins, both approaches agree fairly well. Further, we evaluated the capability of the climate sensitivity approaches to predict a change in streamflow, on the basis of observed variations in the climate of the second part of the 20th century. The combination with the conceptual framework of Tomer and Schilling (2009) and the statistical classification to discern climate from basin characteristic changes yields comprehensive insights into the hydroclimatic changes in the US. We can reinstate that increased annual precipitation leads to increases of streamflow and evapotranspiration in general. However, our results provide evidence that changes in basin characteristics influenced how the additional amount of water is partitioned at the surface. 
Particularly the mapping of $\omega$, describing changes in partitioning of water and energy fluxes at the land surface, yields a quick overview of dominant impacts on streamflow. The resultant patterns are spatially coherent and in agreement with previous studies. The quantitative separation of impacts of basin changes on streamflow supports the hypothesis that humans directly and indirectly alter water resources at the regional and large basin scale. Most prominent are changes in the seasonality of climate due to increased global greenhouse gas emissions (Thomson, 1995; Barnett et al., 2008) and intensified agricultural land use, especially by artificial drainage and irrigation. The results suggest that the direction and magnitude of human impacts distinctly vary with climate, soil, land-use and hydrographic conditions.

Still, changes in basin characteristics and uncertainties, which are essentially attributed to basin characteristic changes, might have had trends in the past but cannot be extrapolated to the future. However, these impacts play a role and one needs to consider such changes when applying any kind of climate sensitivity framework.

\section{Appendix A}

\section{Mathematical derivations for the Mezentsev (1955) function}

The first-order perturbation of the Mezentsev function in Eq. (8) provides analytical solutions for the problem of streamflow sensitivity. Here, the respective partial differentials are given (Roderick and Farquhar, 2011):

$$
\begin{aligned}
\frac{\partial E_{\mathrm{T}}}{\partial P} & =\frac{E_{\mathrm{T}}}{P}\left(\frac{E_{\mathrm{p}}^{n}}{P^{n}+E_{\mathrm{p}}^{n}}\right) \\
\frac{\partial E_{\mathrm{T}}}{\partial E_{\mathrm{p}}} & =\frac{E_{\mathrm{T}}}{E_{\mathrm{p}}}\left(\frac{P^{n}}{P^{n}+E_{\mathrm{p}}^{n}}\right) \\
\frac{\partial E_{\mathrm{T}}}{\partial n} & =\frac{E_{\mathrm{T}}}{n}\left(\frac{\ln \left(P^{n}+E_{\mathrm{p}}^{n}\right)}{n}-\frac{\left(P^{n} \ln (P)+E_{\mathrm{p}}^{n} \ln \left(E_{\mathrm{p}}\right)\right)}{P^{n}+E_{\mathrm{p}}^{n}}\right)
\end{aligned}
$$

To compute the sensitivity of streamflow to precipitation, we insert Eq. (A1) into the first bracketed term of Eq. (9). Then, by applying the water balance $Q=P-E_{\mathrm{T}}$ and substituting $E_{\mathrm{T}}$ by Eq. (A1), an analytical solution is obtained:

$$
\begin{aligned}
& \varepsilon_{Q, P ; \mathrm{Mez}}=\frac{P}{Q}\left(1-\frac{\partial E_{\mathrm{T}}}{\partial P}\right) \\
& \varepsilon_{Q, P ; \mathrm{Mez}}=1+\frac{E_{\mathrm{p}}\left(1-\frac{E_{\mathrm{p}}^{n}}{P^{n}+E_{\mathrm{p}}^{n}}\right)}{\left(P^{n}+E_{\mathrm{p}}^{n}\right)^{-n}-E_{\mathrm{P}}} .
\end{aligned}
$$

Acknowledgements. This work was kindly supported by Helmholtz Impulse and Networking Fund through Helmholtz Interdisciplinary Graduate School for Environmental Research (HIGRADE) (Bissinger and Kolditz, 2008). We thank Kristina Brust and Rico Kronenberg (TU Dresden) for valuable comments on the manuscript. The manuscript greatly benefited by the comments of Michael Roderick and one anonymous referee. The analysis and graphs are made with Free Open Source Software (F.O.S.S.).

Edited by: E. Zehe

\section{References}

Aguilar, C. and Polo, M. J.: Generating reference evapotranspiration surfaces from the Hargreaves equation at watershed scale, Hydrol. Earth Syst. Sci., 15, 2495-2508, doi:10.5194/hess-152495-2011, 2011.

Allen, R., Smith, M., Pereira, L., and Perrier, A.: An update for the calculation of reference evapotranspiration, ICID Bulletin, 43, 35-92, 1994.

Amatya, D., Skaggs, R., and Gregory, J.: Comparison of methods for estimating REF-ET, J. Irrig. Drain. E.-ASCE, 121, 427-435, 1995.

Arnell, N.: Hydrology and Global Environmental Change, Prentice Hall, 2002.

Arora, V.: The use of the aridity index to assess climate change effect on annual runoff, J. Hydrol., 265, 164-177, 2002.

Barnett, T., Pierce, D., Hidalgo, H., Bonfils, C., Santer, B., Das, T., Bala, G., Wood, A., Nozawa, T., Mirin, A., Cayan, D., and Dettinger, M. D.: Human-induced changes in the hydrology of the western United States, Science, 319, 1080, doi:10.1126/science.1152538, 2008.

Becker, R. A., Wilks, A. R., Brownrigg, R., and Minka, T. P.: Maps: Draw Geographical Maps, available at: http://CRAN.R-project. org/package $=$ maps (last access: 11 November 2011), R package version 2.2-1, 2011.

Bissinger, V. and Kolditz, O.: Helmholtz Interdisciplinary Graduate School for Environmental Research (HIGRADE), GAIA, 17, 7173, 2008.

Blöschl, G. and Montanari, A.: Climate change impacts throwing the dice?, Hydrol. Process., 24, 374-381, doi:10.1002/hyp.7574, 2010.

Budyko, M.: Evaporation under natural conditions, Gidrometeorizdat, Leningrad, English translation by IPST, Jerusalem, 1948.

Budyko, M.: Climate and life, Academic press, New York, USA, 1974.

Dinnes, D., Karlen, D., Jaynes, D., Kaspar, T., Hatfield, J., Colvin, T., and Cambardella, C.: Nitrogen management strategies to reduce nitrate leaching in tile-drained Midwestern soils, Agron. J., 94, 153-171, 2002.

Donohue, R. J., Roderick, M. L., and McVicar, T. R.: On the importance of including vegetation dynamics in Budyko's hydrological model, Hydrol. Earth Syst. Sci., 11, 983-995, doi:10.5194/hess11-983-2007, 2007.

Donohue, R. J., McVicar, T. R., and Roderick, M. L.: Assessing the ability of potential evaporation formulations to capture the dynamics in evaporative demand within a changing climate, J. Hydrol., 386, 186-197, doi:10.1016/j.jhydrol.2010.03.020, 2010. 
Dooge, J.: Sensitivity of runoff to climate change: A Hortonian approach, B. Am. Meteorol. Soc., 73, 2013-2024, 1992.

Farnsworth, R. and Thompson, E.: Mean monthly, seasonal, and annual pan evaporation for the United States, National Oceanic and Atmospheric Administration, National Weather Service, 34, 88 pp., 1982.

Groisman, P., Knight, R., Karl, T., Easterling, D., Sun, B., and Lawrimore, J.: Contemporary changes of the hydrological cycle over the contiguous United States: Trends derived from in situ observations, J. Hydrometeorol., 5, 64-85, 2004.

Hamon, W. R.: Computation of direct runoff amounts from storm rainfall, International Association of Scientific Hydrology, 63, 52-62, 1963.

Hargreaves, G. and Allen, R.: History and evaluation of Hargreaves evapotranspiration equation, J. Irrig. Drain. E.-ASCE, 129, 5363, 2003.

Hargreaves, G., Hargreaves, G., and Riley, J.: Irrigation water requirements for Senegal river basin, J. Irrig. Drain. E.-ASCE, 111, 265-275, 1985.

Hijmans, R. J. and van Etten, J.: raster: Geographic analysis and modeling with raster data, available at: http://CRAN.R-project. org/package=raster (last access: 1 August 2012), R package version 1.9-92, 2012.

Jones, J.: Hydrologic responses to climate change: considering geographic context and alternative hypotheses, Hydrol.1 Process., 25, 1996-2000, 2011.

Klemes, V.: Conceptualization and scale in hydrology, J. Hydrol., $65,1-23,1983$.

Kochendorfer, J. and Hubbart, J.: The Roles of Precipitation Increases and Rural Land-Use Changes in Streamflow Trends in the Upper Mississippi River Basin, Earth Interact., 14, 1-12, 2010.

Krakauer, N. Y. and Fung, I.: Mapping and attribution of change in streamflow in the coterminous United States, Hydrol. Earth Syst. Sci., 12, 1111-1120, doi:10.5194/hess-12-1111-2008, 2008.

Kuhnel, V., Dooge, J., O'Kane, J., and Romanowicz, R.: Partial analysis applied to scale problems in surface moisture fluxes, Surv. Geophys., 12, 221-247, 1991.

Kustu, M., Fan, Y., and Robock, A.: Large-scale water cycle perturbation due to irrigation pumping in the US High Plains: A synthesis of observed streamflow changes, J. Hydrol., 390, 222-244, doi:10.1016/j.jhydrol.2010.06.045, 2010.

Lettenmaier, D., Wood, E., and Wallis, J.: Hydro-climatological trends in the continental United States, 1948-88, J. Climate, 7, 586-607, 1994.

Lins, H. and Slack, J.: Streamflow trends in the United States, Geophys. Res. Lett., 26, 227-230, 1999.

Lu, J., Sun, G., McNulty, S., and Amatya, D.: A comparison of six potential evapotranspiration methods for regional use in the southeastern united states, J. Am. Water Resour. As., 41, 621633, 2005.

McCabe, G. and Wolock, D.: A step increase in streamflow in the conterminous United States, Geophys. Res. Lett., 29, 38-1, doi:10.1029/2002GL015999, 2002.

McGuire, V.: Water-level changes in the High Plains aquifer, predevelopment to 2007, 2005-06, and 2006-07, Publications of the US Geological Survey, p. 17, 2009.

Mezentsev, V.: More on the calculation of average total evaporation, Meteorol. Gidrol, 5, 24-26, 1955.
Milliman, J., Farnsworth, K., Jones, P., Xu, K., and Smith, L.: Climatic and anthropogenic factors affecting river discharge to the global ocean, 1951-2000, Global Planet. Change, 62, 187-194, 2008.

Milly, P.: Climate, soil water storage, and the average annual water balance, Water Resour. Res., 30, 2143-2156, 1994.

Milly, P. and Dunne, K.: Trends in evaporation and surface cooling in the Mississippi River basin, Geophys. Res. Lett., 28, 12191222, doi:10.1029/2000GL012321, 2001.

Mitchell, T. and Jones, P.: An improved method of constructing a database of monthly climate observations and associated highresolution grids, Int. J. Climatol., 25, 693-712, 2005.

Ol'Dekop, E.: On evaporation from the surface of river basins, Transactions on meteorological observations University of Tartu, Vol. 4, 200 pp., 1911.

Oudin, L., Andréassian, V., Lerat, J., and Michel, C.: Has land cover a significant impact on mean annual streamflow? An international assessment using 1508 catchments, J. Hydrol., 357, 303316, doi:10.1016/j.jhydrol.2008.05.021, 2008.

Pavelis, G.: Farm drainage in the United States: history, status, and prospects, Miscellaneous publication/United States, Dept. of Agriculture, Washington, DC, 1987.

Qian, T., Dai, A., and Trenberth, K.: Hydroclimatic Trends in the Mississippi River Basin from 1948 to 2004, J. Climate, 20, 45994614, doi:10.1175/JCLI4262.1, 2007.

R Development Core Team: R: A Language and Environment for Statistical Computing, R Foundation for Statistical Computing, Vienna, Austria, available at: http://www.R-project.org/, ISBN 3900051-07-0, 2011.

Raymond, P., Oh, N., Turner, R., and Broussard, W.: Anthropogenically enhanced fluxes of water and carbon from the Mississippi River, Nature, 451, 449-452, doi:10.1038/nature06505, 2008.

Renner, M., Seppelt, R., and Bernhofer, C.: Evaluation of waterenergy balance frameworks to predict the sensitivity of streamflow to climate change, Hydrol. Earth Syst. Sci., 16, 1419-1433, doi:10.5194/hess-16-1419-2012, 2012.

Roderick, M. and Farquhar, G.: A simple framework for relating variations in runoff to variations in climatic conditions and catchment properties, Water Resour. Res., 47, W00G07, doi:10.1029/2010WR009826, 2011.

Sankarasubramanian, A., Vogel, R., and Limbrunner, J.: Climate elasticity of streamflow in the United States, Water Resour. Res., 37, 1771-1781, 2001.

Schaake, J. and Liu, C.: Development and application of simple water balance models to understand the relationship between climate and water resources, in: New Directions for Surface Water Modeling Proceedings of the Baltimore Symposium, 1989.

Schaake, J., Cong, S., and Duan, Q.: The US MOPEX data set, Wallingford, Oxfordshire, IAHS-AISH P., 307, 9-28, 2006.

Schreiber, P.: Über die Beziehungen zwischen dem Niederschlag und der Wasserführung der Flüsse in Mitteleuropa, Z. Meteorol., 21, 441-452, 1904.

Small, D., Islam, S., and Vogel, R.: Trends in precipitation and streamflow in the eastern US: Paradox or perception, Geophys. Res. Lett., 33, L03403, doi:10.1029/2005GL024995, 2006.

Thomson, D.: The seasons, global temperature, and precession, Science, 268, 59-68, 1995.

Tomer, M. and Schilling, K.: A simple approach to distinguish landuse and climate-change effects on watershed hydrology, J. Hy- 
drol., 376, 24-33, doi:10.1016/j.jhydrol.2009.07.029, 2009.

Troch, P., Martinez, G., Pauwels, V., Durcik, M., Sivapalan, M., Harman, C., Brooks, P., Gupta, H., and Huxman, T.: Climate and vegetation water use efficiency at catchment scales, Hydrol. Process., 23, 2409-2414, doi:10.1002/hyp.7358, 2009.

Turner, R. and Rabalais, N.: Coastal eutrophication near the Mississippi river delta, Nature, 368, 619-621, 1994.

Voepel, H., Ruddell, B., Schumer, R., Troch, P. A., Brooks, P. D., Neal, A., Durcik, M., and Sivapalan, M.: Quantifying the role of climate and landscape characteristics on hydrologic partitioning and vegetation response, Water Resour. Res., 47, W00J09, doi:10.1029/2010WR009944, 2011.

Walter, M., Wilks, D., Parlange, J., and Schneider, R.: Increasing Evapotranspiration from the Conterminous United States, J. Hydrometeorol., 5, 405-408, 2004.
Wang, D. and Cai, X.: Comparative study of climate and human impacts on seasonal baseflow in urban and agricultural watersheds, Geophys. Res. Lett., 37, L06406, doi:10.1029/2009GL041879, 2010.

Wang, D. and Hejazi, M.: Quantifying the relative contribution of the climate and direct human impacts on mean annual streamflow in the contiguous United States, Water Resour. Res., 47, W00J12, doi:10.1029/2010WR010283, 2011.

Yang, H. and Yang, D.: Derivation of climate elasticity of runoff to assess the effects of climate change on annual runoff, Water Resour. Res., 47, W07526, doi:10.1029/2010WR009287, 2011. 